\title{
A randomized, placebo-controlled study of the cardiovascular safety of the once-weekly DPP-4 inhibitor omarigliptin in patients with type 2 diabetes mellitus
}

Ira Gantz ${ }^{1,2^{*}} \oplus$, Menghui Chen ${ }^{1,3}$, Shailaja Suryawanshi ${ }^{1,3}$, Catherine Ntabadde ${ }^{1,4}$, Sukrut Shah ${ }^{1,5}$, Edward A. O'Neill ${ }^{1,6}$, Samuel S. Engel ${ }^{1,7}$, Keith D. Kaufman $^{1,8}$ and Eseng Lai ${ }^{1,9}$

\begin{abstract}
Background: Omarigliptin is a once-weekly (q.w.) oral DPP-4 inhibitor that is approved for the treatment of patients with type 2 diabetes mellitus (T2DM) in Japan. To support approval of omarigliptin in the United States, the clinical development program included a cardiovascular (CV) safety study. Subsequently, a business decision was made not to submit a marketing application for omarigliptin in the United States, and the CV safety study was terminated. Herein we report an analysis of data from that early-terminated study.

Methods: In this randomized, double-blind study, 4202 patients with T2DM and established CV disease were assigned to either omarigliptin $25 \mathrm{mg}$ q.w. or matching placebo in addition to their existing diabetes therapy. A Cox proportional hazards model was used to summarize the primary endpoint of time to first major adverse CV event (MACE, the composite of CV death, nonfatal myocardial infarction, and nonfatal stroke) and the analysis of first event of hospitalization for heart failure (hHF).

Results: The median follow-up was approximately 96 weeks (range 1.1-178.6 weeks). The primary MACE outcome occurred in 114/2092 patients in the omarigliptin group (5.45\%; 2.96/100 patient-years) and 114/2100 patients in the placebo group (5.43\%; 2.97/100 patient-years), with a hazard ratio (HR) of 1.00 (95\% confidence interval [CI] 0.77, 1.29). The hHF outcome occurred in 20/2092 patients in the omarigliptin group (0.96\%; 0.51/100 patient-years) and 33/2100 patients in the placebo group (1.57\%; 0.85/100 patient-years), with an HR of 0.60 ( $95 \% \mathrm{Cl} 0.35,1.05)$. After 142 weeks, the least-squares mean difference (omarigliptin vs. placebo) in glycated hemoglobin levels was $-0.3 \%(95 \% \mathrm{Cl}-0.46$, $-0.14)$. The numbers of patients with adverse events, serious adverse events or discontinued from study medication due to adverse events were similar in the omarigliptin and placebo groups.
\end{abstract}

Conclusions: In this CV safety study of patients with T2DM and established CV disease, omarigliptin did not increase the risk of MACE or hHF and was generally well tolerated.

Trial registration ClinicalTrials.gov: NCT01703208. Registered 05 October 2012

Keywords: Antihyperglycemic agent, Dipeptidyl peptidase-4, Incretin, MK-3102

\section{Background}

Omarigliptin is an oral dipeptidyl peptidase-4 (DPP-4) inhibitor for the treatment of type 2 diabetes mellitus

\footnotetext{
*Correspondence: ira.gantz@merck.com

2 Merck \& Co., Inc., RY34-A260, P.O. Box 2000, Rahway, NJ 07065, USA

Full list of author information is available at the end of the article
(T2DM) with a half-life that allows once-weekly dosing [1]. Omarigliptin has previously been demonstrated to have efficacy comparable to that of the daily DPP- 4 inhibitor sitagliptin [2,3]. Omarigliptin has been marketed in Japan (as MARIZEV ${ }^{\mathrm{TM}}$ ) for the treatment of patients with T2DM since 2015. 
When the omarigliptin Phase 3 development program was initiated in 2012, it was designed to support the approval of omarigliptin in multiple countries, including the United States (US). However, on April 8, 2016, the Sponsor, Merck \& Co., Inc., Kenilworth, NJ, USA (known as MSD outside of the US and Canada), announced it would not proceed with submitting marketing applications for omarigliptin in the US or Europe. The decision was made for business reasons and was not related to safety or efficacy concerns about omarigliptin.

The omarigliptin Phase 3 program included a dedicated cardiovascular (CV) safety study (MK-3102-018; ClinicalTrials.gov NCT01703208), which was being conducted to meet the US Food and Drug Administration requirement to establish the $\mathrm{CV}$ safety of new therapies to treat T2DM to ensure that the therapy does not result in an unacceptable increase in CV risk. As part of this requirement, both pre-approval and post-approval assessments of $\mathrm{CV}$ safety were to be done, with the former met (based on a pooled analysis of adjudicationconfirmed CV events from the Phase 3 program) and the latter requiring analysis of major adverse $\mathrm{CV}$ events (MACE), defined as the composite endpoint of first adjudication-confirmed event of $\mathrm{CV}$ death, nonfatal myocardial infarction (MI) or nonfatal stroke, based solely on the results of MK-3102-018. After the announcement by the Sponsor that approval of omarigliptin would not be pursued in the US or Europe, the CV safety study was no longer required to meet post-approval requirements and the study was terminated.

Three CV safety studies for the daily DPP-4 inhibitors saxagliptin (SAVOR-TIMI 53), alogliptin (EXAMINE) and sitagliptin (TECOS) have been completed and the results of these studies have significantly contributed to the scientific understanding of the $\mathrm{CV}$ safety of the DPP-4 inhibitor drug class [4-6]. These studies, which collectively randomized more than 36,500 patients (in a 1:1 ratio) to a daily DPP-4 inhibitor or placebo on a background of standard care, suggest that daily DPP-4 inhibitors are not associated with an increased risk for MACE, with the point estimates of the hazard ratios (HRs) for MACE approximately 1.0 in all three studies. An unexpected finding in SAVOR-TIMI 53 was that of an increased risk of hospitalization for HF (hHF) with saxagliptin (3.5\% saxagliptin vs. $2.8 \%$ placebo; HR 1.27 ; 95\% confidence interval [CI] 1.07, 1.51; $\mathrm{p}=0.007$ ) [6]. The EXAMINE study enrolled a post-acute coronary syndrome (ACS) population and did not show a statistically significant increased risk of hHF (3.9\% alogliptin vs. 3.3\% placebo; HR 1.19; 95\% CI 0.90-1.58; $p=0.220$ ) [7]. In TECOS, the incidence of hHF was similar in the sitagliptin and placebo groups (3.1\% sitagliptin vs. $3.1 \%$ placebo; HR 1.00; 95\% CI 0.83, 1.20; $\mathrm{p}=0.98$ ) [4]. These studies also served as sources of data to explore the overall safety of the DPP-4 inhibitor drug class, including pancreatic safety [8]. A meta-analysis suggested a small absolute increased risk for pancreatitis with DPP-4 inhibitor therapy (risk ratio 1.78 [95\% CI 1.13, 2.81], $\mathrm{p}=0.01$ ), but not for pancreatic cancer (risk ratio 0.54 [95\% CI 0.28, 1.04], $\mathrm{p}=0.07)[8]$.

Herein we report the results of an analysis of CV endpoints and non-CV safety from the omarigliptin $\mathrm{CV}$ safety study (MK-3102-018), based on the data accrued up to the date of May 13, 2016, which was approximately 30 days after the announcement of study discontinuation. The rationale for a May 13, 2016 data cut-off date was to facilitate completion of the study and analysis of results. At the time of the data cut-off date, 403/4192 patients had not yet reached their final study visit, although most of these were discontinued shortly afterwards.

\section{Methods}

\section{Patients}

Eligible patients were at least 40 years old with a history of T2DM and established CV disease. Patients were required to be on one of the following diabetes treatment regimens that was stable for at least 12 weeks (except for pioglitazone which was required to be stable for at least 16 weeks) and be within the glycated hemoglobin (HbA1c) range associated with the treatment regimen (Fig. 1). Patients on diet and exercise alone (not on an AHA for $\geq 12$ weeks) or on monotherapy or dual combination therapy with metformin (MF), pioglitazone (PIO), an alpha-glucosidase inhibitor (AGI) or an SGLT2 inhibitor (SGLT2i) were required to have an HbA1c of $\geq 6.5$ and $\leq 10.0 \%(\geq 48$ and $\leq 86 \mathrm{mmol} / \mathrm{mol})$. Patients on a sulfonylurea or meglitinide either as monotherapy or as part of dual combination therapy with MF, PIO, AGI or an SGLT2i were required to have an HbA1c $\geq 7.0$ and $\leq 10.0 \%$ ( $\geq 53 \mathrm{mmol} / \mathrm{mol}$ and $\leq 86 \mathrm{mmol}$ ). Patients could also be enrolled if they were on a stable insulin regimen ( \pm metformin) with an $\mathrm{HbA1c} \geq 7.0$ and $\leq 10.0 \%(\geq 53 \mathrm{mmol} / \mathrm{mol}$ and $\leq 86 \mathrm{mmol})$. Insulin regimens that were allowed included basal insulin (e.g., insulin glargine, insulin detemir, NPH insulin, degludec), prandial insulin (e.g., regular, aspart, lispro, glulisine), basal/prandial insulin regimen consisting of multiple dose insulin injections of basal and prandial insulin or the use of pre-mixed insulin (e.g., Novolog $70 / 30^{\circledR}$, Novolin $70 / 30^{\circledR}$, Humalog $75 / 25^{\circledR}$, or Humulin $70 / 30^{\circledR}$ ). A stable insulin regimen was defined as no change in the insulin regimen [i.e. type(s) of insulin] and $\leq 10 \%$ change in the total daily dose of insulin. Prior to randomization, patients were required to have a site fasting-fingerstick glucose (FFSG) $>126 \mathrm{mg} / \mathrm{dL}(7.0 \mathrm{mmol} / \mathrm{L})$ and $<260 \mathrm{mg} /$ $\mathrm{dL}(14.4 \mathrm{mmol} / \mathrm{L})$. 


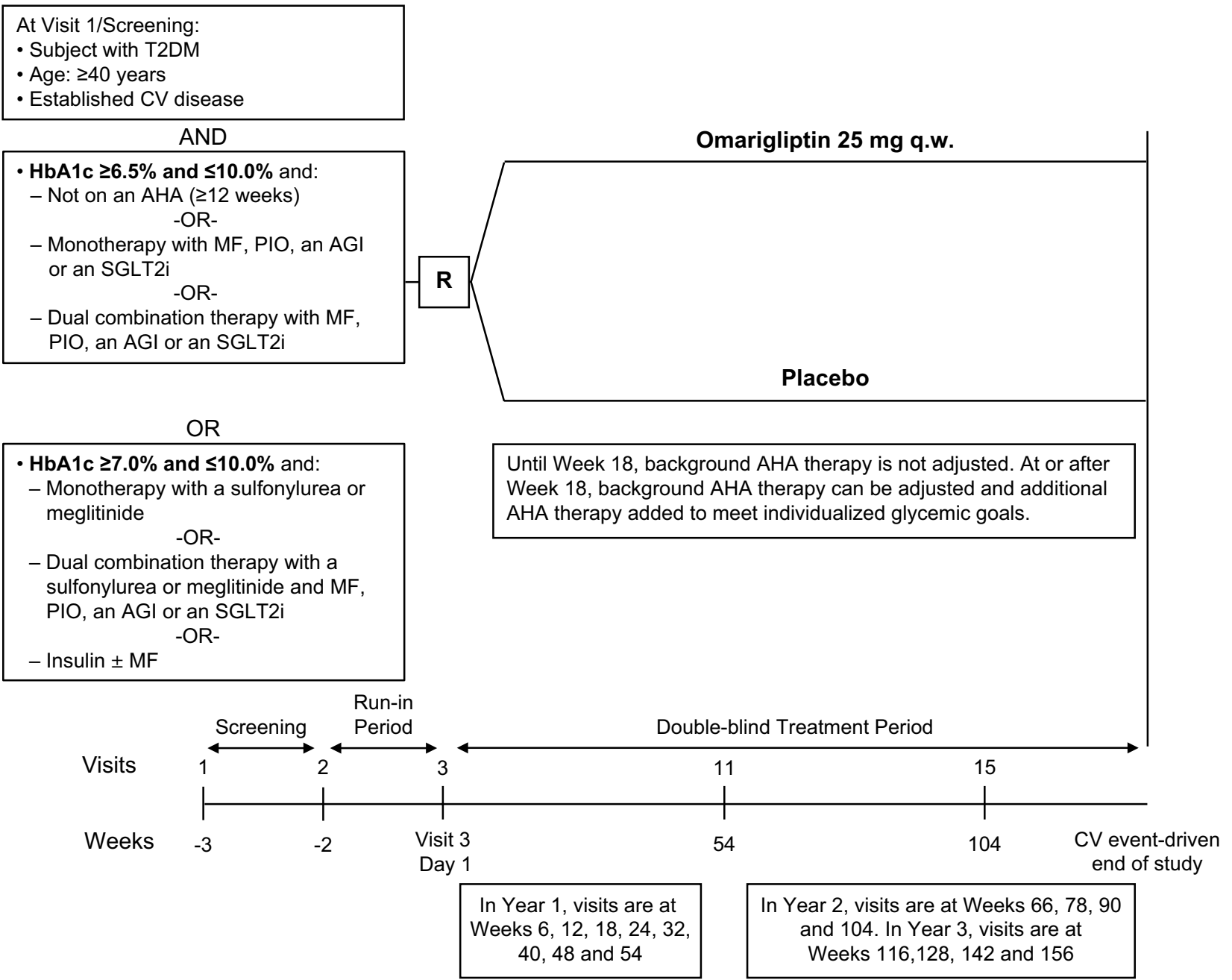

Fig. 1 Study design; T2DM type 2 diabetes, CV cardiovascular, AHA antihyperglycemic agent, MF metformin, PIO pioglitazone, AG/ alpha-glucosidase inhibitor, SGLT2i sodium-glucose co-transporter 2 inhibitor, SU sulfonylurea, q.W. once weekly, R randomization

The criteria for having established CV disease included the presence of one of the following: (1) coronary artery disease defined as having a history of MI, surgical or percutaneous (balloon and/or stent) coronary revascularization procedure, or coronary angiography showing at least 1 stenosis $\geq 50 \%$ in a major epicardial artery or branch vessel; (2) ischemic cerebrovascular disease defined as having a history of ischemic stroke (strokes not known to be hemorrhagic will be allowed as part of this criterion); (3) carotid arterial disease defined as a $\geq 50 \%$ stenosis documented by carotid ultrasound, magnetic resonance imaging, or angiography, with or without symptoms of neurologic deficit; or (4) atherosclerotic peripheral arterial disease, as documented by objective evidence such as amputation due to vascular disease, current symptoms of intermittent claudication confirmed by an ankle-brachial pressure index of $<0.9$ or a toe-brachial pressure index $<0.7$ or history of surgical or percutaneous revascularization procedure.

Patients were excluded if they had acute coronary syndrome (e.g., MI or unstable angina), a coronary artery intervention (e.g., CABG or PTCA), a stroke or transient ischemic neurological disorder or worsening signs or symptoms of coronary heart disease or congestive heart failure within the past 3 months; type 1 diabetes, a history of ketoacidosis, or C-peptide $<0.7 \mathrm{ng} / \mathrm{mL}$; estimated glomerular filtration rate $<40 \mathrm{~mL} / \mathrm{min} / 1.73 \mathrm{~m}^{2}$; active liver disease or an aspartate aminotransferase (AST) or alanine aminotransferase (ALT) level $>2 \times$ the upper limit of normal (ULN); thyroid stimulating hormone outside the central laboratory normal range; triglycerides $>600 \mathrm{mg} / \mathrm{dL}(6.78 \mathrm{mmol} / \mathrm{L})$; hemoglobin $<12 \mathrm{~g} / \mathrm{dL}$ 
$(120 \mathrm{~g} / \mathrm{L})($ males $)$ and < $11 \mathrm{~g} / \mathrm{dL}(110 \mathrm{~g} / \mathrm{L})$ (females); history of malignancy or hematological disorders; or previously treated with omarigliptin.

\section{Study design}

This multicenter, double-blind, randomized, placebocontrolled, parallel group, Phase 3 study (Fig. 1) was conducted in 559 centers: 10 in Argentina, 7 in Australia, 5 in Austria, 10 in Belgium, 16 in Brazil, 6 in Bulgaria, 7 in Canada, 4 in Chile, 6 in Colombia, 6 in Croatia, 11 in the Czech Republic, 7 in Denmark, 2 in Finland, 5 in France, 15 in Georgia, 24 in Germany, 8 in Hong Kong, 8 in Hungary, 11 in Israel, 14 in Italy, 4 in Lebanon, 5 in Lithuania, 9 in Malaysia, 4 in Mexico, 5 in the Netherlands, 7 in New Zealand, 12 in the Philippines, 14 in Poland, 11 in the Republic of Korea, 16 in Romania, 12 in the Russian Federation, 5 in Serbia, 11 in Slovakia, 20 in South Africa, 15 in Spain, 9 in Sweden, 6 in the province of Taiwan, 16 in the Ukraine, 16 in the United Kingdom and 180 in the United States. Patients were randomly assigned in a 1:1 ratio to omarigliptin $25 \mathrm{mg}$ q.w. or placebo using an interactive voice-response system.

After Week 18, patients were to have their background AHA regimen adjusted as deemed necessary by the study investigator to achieve an appropriate individualized glycemic goal in line with local, national or international guidelines. Whenever possible, the patients were followed until study closeout, regardless of whether they continued to receive blinded study medication. The study was designed and funded by the Sponsor and conducted in conjunction with PAREXEL International Corp., Waltham, MA.

The study (Omarigliptin Protocol 018; ClinicalTrials.gov: NCT01703208) was conducted in accordance with the principles of Good Clinical Practice and was approved by the appropriate institutional review boards and regulatory agencies. All patients enrolled in the study provided written informed consent.

\section{Study evaluations}

Safety assessment included collection of adverse events, physical examination, vital signs, standard laboratory blood chemistry (e.g., liver and renal safety tests), lipid panel, hematology, urinalysis and electrocardiogram. In addition, amylase and lipase were measured per regulatory agency request. A standard questionnaire was provided to patients to collect hypoglycemia information.

An external Data Monitoring Committee reviewed unblinded interim data from this study. External Clinical Adjudication Committees (CACs) evaluated potential $\mathrm{CV}$ events, cases of pancreatitis and prespecified hypersensitivity reactions in a blinded manner. The CACs were not charged with assessing causality to study medication. The adjudication of hypersensitivity was at the request of regulatory authorities and was not due to any signal observed with omarigliptin. Hypersensitivity events prespecified for adjudication were anaphylactic reaction, angioedema, asthma-bronchospasm, erythema multiforme, Stevens-Johnson syndrome, toxic epidermal necrolysis, and drug rash with eosinophilia and systemic symptoms.

\section{Endpoints}

$\mathrm{CV}$ endpoints analyzed included (1) time to first event of MACE (confirmed CV-related death, nonfatal MI, nonfatal stroke); (2) time to confirmed CV-related death; (3) time to first event of confirmed MI (fatal and nonfatal); (4) time to first event of stroke (fatal and nonfatal); (5) time to all-cause mortality; (6) time to first event of confirmed hHF; and (7) time to the composite of first confirmed event hHF or CV death. Change from baseline over time in HbA1c and non-CV safety, including hypoglycemia, was analyzed. Criteria for the adjudication of CV endpoints followed guidelines of the Clinical Data Interchange Standards Consortium for standardized definition of CV [9] and stroke endpoints in clinical trials and the Third Universal Definition of Myocardial Infarction [10], as excerpted in Additional file 1.

\section{Statistical analyses}

The number of patients randomized was based on the primary hypothesis of the study, which was non-inferiority of omarigliptin compared with placebo for the primary composite MACE endpoint. Non-inferiority was to be declared if the upper bound of the two-sided 95\% confidence interval (CI) of the HR for MACE was $<1.30$ in the intention-to-treat (ITT) population and was to include all confirmed events that occurred up to 365 days after last dose of blinded study medication. A total of 632 patients having a primary endpoint event would provide $90 \%$ power for the test of non-inferiority, assuming a true HR of 1.00. It was estimated that the study would take approximately 8 years from initiation to completion, assuming accrual of primary endpoints at 3.0\% per year and rates of enrollment and patient dropout.

Due to the early termination of the study and the attendant decrease in power to adequately test the primary hypothesis of non-inferiority, no formal statistical testing of the non-inferiority hypothesis was conducted. The population analyzed was the ITT population that included all randomized patients who took at least 1 dose of blinded study medication and all CV endpoint data, regardless of the time since a patient may have discontinued blinded study medication. 
The analyses presented herein encompass the time period from first-patient-first-visit (October 16, 2012) to the final data cut-off date (May 13, 2016). The data cut-off date was approximately 30 days after investigator notification of study discontinuation, which followed the Sponsor's announcement of its intent not to seek marketing authorization for omarigliptin in the US and Europe. At the time of the data cut-off date, 90.4\% of randomized patients had been discontinued from the study. $\mathrm{CV}$ events that occurred after the data cut-off date in the remaining $9.6 \%$ of patients $(n=403 ; 209$ in the omarigliptin group and 194 in the placebo group) who were ongoing in the study at the time of the data cut-off date were not adjudicated and are not included in the analyses presented herein. Nearly all of the ongoing patients were discontinued from blinded study medication shortly afterwards; however, in Brazil, based on local regulatory procedures, 75 patients remained on blinded study medication, with the last patient visit occurring on March 23, 2017.

The ITT population was used for the assessment of $\mathrm{CV}$ endpoints. The Cox proportional-hazards model was used to calculate the HR and two-sided 95\% CI. The Kaplan-Meier method was used to estimate the time-tofirst event in the two treatment groups. The Full Analysis Set, consisting of all randomized patients who received at least 1 dose of study medication and had a baseline or a post-randomization measurement, was used for analyzing the HbA1c endpoint. No subgroup analyses were performed. Safety and tolerability were assessed in the All-Patients-as-Treated (APaT) population, which included all randomized patients who received at least 1 dose of study medication, by clinical review of all relevant parameters, including adverse events, laboratory tests and vital signs.

The primary analysis of safety was assessed in the time frame consisting of the Treatment Period +21 days. Adverse events of symptomatic hypoglycemia (episodes with clinical symptoms attributed to hypoglycemia, without regard to glucose level) were prespecified as events of interest and p values and 95\% CI for between-treatment group comparisons were calculated. Confirmed events of pancreatitis and prespecified hypersensitivity adverse events were summarized regardless of time after discontinuation from study medication. Patients who discontinued blinded study medication and who did not withdraw consent were followed by telephone contact until study end to ascertain any serious adverse events that occurred after the discontinuation of blinded study medication. A second approach to safety analyses, that applied only to serious adverse events, included all safety-related data after the first dose of blinded study medication and was referred to as Treatment Period + all follow-up days.

\section{Results}

Patient disposition and characteristics

Patient disposition is summarized in Table 1. Eight patients randomized to the omarigliptin group and two randomized to the placebo group did not take any study medication and were not included in any safety or efficacy analyses. Demographic and anthropometric characteristics of randomized patients were similar between the two treatment groups (Table 2). Approximately 70\% of patients were male and $30 \%$ female; the mean age was 63.6 years. Racial percentages were $81.3 \%$ White, $10.8 \%$ Asian, 3.8\% Black, and $12.7 \%$ were of Hispanic or Latino ethnicity. The mean BMI was $31.3 \mathrm{~kg} / \mathrm{m}^{2}$. Twenty-one percent of patients were from North America, 55.6\% were from Europe, 6.8\% were from Latin America, 9.1\% were from Asia and 7.6\% were from other countries.

Baseline disease state characteristics are presented in Table 2. The mean baseline HbA1c was $8.0 \%$ and mean duration of T2DM was 12.1 years. The majority of patients $(88.3 \%)$ had an estimated glomerular filtration rate $(\mathrm{eGFR}) \geq 60 \mathrm{~mL} / \mathrm{min} / 1.73 \mathrm{~m}^{2}$ and $11.3 \%$ had an eGFR $\geq 30$ and $<60 \mathrm{~mL} / \mathrm{min} / 1.73 \mathrm{~m}^{2}$. The majority had a history of hypertension (95.4\%) and $15.3 \%$ had a history of heart failure (16.2\% in the omarigliptin group and $14.3 \%$ in the placebo group). The most commonly used prior oral AHA medication was metformin (77.4\%), followed by sulfonylurea (39.1\%) and insulin (34.9\%).

The median duration of exposure to study medication was similar in the two treatment groups: 90.0 weeks (range 1.0-172.0) in the omarigliptin group and 89.0 weeks (range 1.0-168.0) in the placebo group. The median duration of treatment plus post-treatment follow-up was similar in the two treatment groups: 96.1 weeks (range 1.1-178.6) in the omarigliptin group

\section{Table 1 Disposition of patients}

\begin{tabular}{|c|c|c|}
\hline $\begin{array}{l}\text { Study medication disposition, } \\
\mathrm{n}(\%)\end{array}$ & $\begin{array}{l}\text { Omarigliptin } 25 \mathrm{mg} \\
N=2100\end{array}$ & $\begin{array}{l}\text { Placebo } \\
N=2102\end{array}$ \\
\hline Did not take study medication & $8(0.4)$ & $2(0.1)$ \\
\hline Discontinued study medication & 2092 (99.6) & $2100(99.9)$ \\
\hline Adverse event & $88(4.2)$ & $74(3.5)$ \\
\hline Death & $48(2.3)$ & $37(1.8)$ \\
\hline Lack of efficacy & $9(0.4)$ & $14(0.7)$ \\
\hline Lost to follow-up & $44(2.1)$ & $54(2.6)$ \\
\hline Non-compliance with study drug & $10(0.5)$ & $6(0.3)$ \\
\hline Physician decision & $25(1.2)$ & $33(1.6)$ \\
\hline Progressive disease & $2(0.1)$ & $1(0.0)$ \\
\hline Protocol violation & $7(0.3)$ & $14(0.7)$ \\
\hline Study terminated by sponsor & $1615(76.9)$ & $1602(76.2)$ \\
\hline Withdrawal by patient & $197(9.4)$ & $213(10.1)$ \\
\hline Other & $47(2.2)$ & $52(2.5)$ \\
\hline
\end{tabular}


Table 2 Baseline characteristics of study patients

\begin{tabular}{|c|c|c|}
\hline & $\begin{array}{l}\text { Omarigliptin } \\
N=2100\end{array}$ & $\begin{array}{l}\text { Placebo } \\
N=2102\end{array}$ \\
\hline Age, years & $63.7 \pm 8.5$ & $63.6 \pm 8.5$ \\
\hline Male, $n(\%)$ & $1461(69.6)$ & $1487(70.7)$ \\
\hline \multicolumn{3}{|l|}{ Race, $n(\%)$} \\
\hline White & $1707(81.3)$ & $1709(81.3)$ \\
\hline Asian & $234(11.1)$ & $221(10.5)$ \\
\hline Black & $73(3.5)$ & $87(4.1)$ \\
\hline Multi-racial & $67(3.2)$ & $67(3.2)$ \\
\hline American Indian/Alaska Native & $13(0.6)$ & $12(0.6)$ \\
\hline Native Hawaiian or Other Pacific Islander & $6(0.3)$ & $6(0.3)$ \\
\hline \multicolumn{3}{|l|}{ Ethnicity, $n(\%)$} \\
\hline Not Hispanic or Latino & $1813(86.3)$ & $1814(86.3)$ \\
\hline Hispanic or Latino & $267(12.7)$ & $266(12.7)$ \\
\hline Not reported & $13(0.6)$ & $10(0.5)$ \\
\hline Unknown & $7(0.3)$ & $12(0.6)$ \\
\hline Body weight, kg & $89.0 \pm 18.5$ & $89.6 \pm 18.8$ \\
\hline $\mathrm{BMI}, \mathrm{kg} / \mathrm{m}^{2}$ & $31.2 \pm 5.5$ & $31.4 \pm 5.6$ \\
\hline \multicolumn{3}{|l|}{ Geographic region } \\
\hline North America & $431(20.5)$ & $450(21.4)$ \\
\hline Europe & $1166(55.5)$ & $1169(55.6)$ \\
\hline Latin America & $140(6.7)$ & $144(6.9)$ \\
\hline Asia & $201(9.6)$ & $180(8.6)$ \\
\hline Other ${ }^{a}$ & $162(7.7)$ & $159(7.6)$ \\
\hline $\mathrm{HbA} 1 \mathrm{c}, \%$ & $8.0 \pm 0.9$ & $8.0 \pm 0.9$ \\
\hline Duration of diabetes, years & $12.0 \pm 7.6$ & $12.1 \pm 8.0$ \\
\hline eGFR (mL/min/1.73 m²) & $85.7 \pm 24.5$ & $86.6 \pm 25.5$ \\
\hline History of congestive heart failure & $341(16.2)$ & $300(14.3)$ \\
\hline History of hypertension & $1998(95.1)$ & $2010(95.6)$ \\
\hline \multicolumn{3}{|l|}{ Cigarette smoking status } \\
\hline Current & $301(14.3)$ & $305(14.5)$ \\
\hline Former & $825(39.3)$ & $815(38.8)$ \\
\hline Never & $974(46.4)$ & $981(46.7)$ \\
\hline Unknown & $0(0.0)$ & $1(0.0)$ \\
\hline \multicolumn{3}{|l|}{ Prior AHA therapy } \\
\hline Insulin & 769 (36.6) & $699(33.3)$ \\
\hline Metformin & $1646(78.4)$ & $1606(76.4)$ \\
\hline Sulfonylurea & $817(38.9)$ & $826(39.3)$ \\
\hline SGLT2 inhibitor & $4(0.2)$ & $4(0.2)$ \\
\hline Thiazolidinedione & $24(1.1)$ & $21(1.0)$ \\
\hline Other & $55(2.6)$ & $55(2.6)$ \\
\hline None & $71(3.4)$ & $84(4.0)$ \\
\hline
\end{tabular}

Values are mean \pm SD or $\mathrm{n}(\%)$

$B M I$ body mass index, eGFR estimated glomerular filtration rate, $A H A$ antihyperglycemic agent, SGLT2 sodium-glucose linked transporter 2

a For geographic region, other includes Australia, Israel, Lebanon, New Zealand and South Africa

and 95.6 weeks (range 1.3-176.0) in the placebo group. Mean compliance with study medication (omarigliptin or matching placebo) was similar for the two treatment groups (97.8 and $97.9 \%$ for omarigliptin and placebo, respectively).

\section{$\mathrm{CV}$ endpoints}

Table 3 summarizes the results of the CV endpoints analyzed. There was no significant between-group difference in the composite MACE endpoint, which occurred in $114 / 2092$ patients in the omarigliptin group (5.45\%) and $114 / 2100$ patients in the placebo group (5.43\%).

Figure 2 presents the Kaplan-Meier plot of time to first MACE event. There was no notable treatment difference in event rates over time through Week 156.

The rate of confirmed MACE per 100 patient-years was 2.96 for omarigliptin and 2.97 for placebo (HR, 1.00; 95\% CI, 0.77-1.29). The rate of confirmed CV-related death per 100 patient-years was 0.94 for omarigliptin and 0.89 for placebo, with an HR $(95 \% \mathrm{CI})$ of $1.06(0.66,1.68)$. The rate of confirmed fatal or non-fatal MI per 100 patientyears was 1.34 for omarigliptin and 1.55 for placebo, with an HR $(95 \% \mathrm{CI})$ of $0.87(0.60,1.26)$. The rate of confirmed fatal or non-fatal stroke per 100 patient-years was 0.82 for omarigliptin and 0.88 for placebo, with an HR (95\% CI) of $0.94(0.58,1.52)$. The rate of all-cause mortality per 100 patient-years was 1.63 for omarigliptin and 1.28 for placebo, with an HR $(95 \% \mathrm{CI})$ of $1.28(0.88,1.85)$. There was no specific pattern of non-CV deaths. Figure 3 presents a forest plot of MACE and other $\mathrm{CV}$ endpoints (CV-related death, fatal and nonfatal MI, fatal and nonfatal stroke and all-cause mortality).

There was no significant difference in the rate of hHF or the rate of the composite of hHF and CV death. The rate of first hHF per 100 patient-years was 0.51 for omarigliptin and 0.85 for placebo, with an $\mathrm{HR}(95 \% \mathrm{CI})$ of $0.60(0.35,1.05)$. The rate of the composite endpoint of first hHF or CV death per 100 patient-years was 1.41 for omarigliptin and 1.65 for placebo, with an $\mathrm{HR}(95 \% \mathrm{CI})$ of $0.86(0.60,1.23)$.

\section{Change from baseline in $\mathrm{HbA1c}$}

The changes from baseline in HbA1c over time (up to Week 142) are shown in Fig. 4. At Week 18, prior to the adjustment of background medication to meet individualized patient goals (see above), from a mean baseline $\mathrm{HbA1c}$ of $8.0 \%$, the LS mean change from baseline $(95 \% \mathrm{CI})$ in $\mathrm{HbA} 1 \mathrm{c}$ was $-0.58 \%(-0.62,-0.55)$ in the omarigliptin group and $-0.16 \%(-0.19,-0.12)$ in the placebo group, with a between treatment difference of $-0.43 \%(-0.48,-0.37)$. The profile of the change in HbA1c over time indicates that the between-group difference persisted throughout the treatment period. At Week 142, the change from baseline (95\% CI) was $-0.36 \%(-0.47,-0.25)$ in the omarigliptin group and $-0.06 \%(-0.17,0.05)$ in the placebo group, with a 
Table 3 Cardiovascular endpoints in the ITT population; Treatment Period + all follow-up days

\begin{tabular}{|c|c|c|c|c|c|}
\hline \multirow[t]{2}{*}{ Endpoint } & \multicolumn{2}{|c|}{ Number of events (\%) } & \multicolumn{2}{|c|}{ Rate/100 patient-years ${ }^{\mathrm{a}}$} & \multirow{2}{*}{$\begin{array}{l}\text { Hazard ratio of omarigliptin } \\
\text { vs. placebo }(95 \% \mathrm{Cl})^{\mathrm{b}}\end{array}$} \\
\hline & $\begin{array}{l}\text { Omarigliptin } \\
N=2092\end{array}$ & $\begin{array}{l}\text { Placebo } \\
N=2100\end{array}$ & Omarigliptin & Placebo & \\
\hline $\begin{array}{l}\text { Cardiovascular death, nonfatal myocardial } \\
\text { infarction or nonfatal stroke }\end{array}$ & $114(5.45)$ & $114(5.43)$ & 2.96 & 2.97 & $1.00(0.77,1.29)$ \\
\hline Cardiovascular-related death & $37(1.77)$ & $35(1.67)$ & 0.94 & 0.89 & $1.06(0.66,1.68)$ \\
\hline Fatal and nonfatal myocardial infarction & $52(2.49)$ & $60(2.86)$ & 1.34 & 1.55 & $0.87(0.60,1.26)$ \\
\hline Fatal and nonfatal stroke & $32(1.53)$ & $34(1.62)$ & 0.82 & 0.88 & $0.94(0.58,1.52)$ \\
\hline All-cause mortality & $64(3.06)$ & $50(2.38)$ & 1.63 & 1.28 & $1.28(0.88,1.85)$ \\
\hline Hospitalization for heart failure & $20(0.96)$ & $33(1.57)$ & 0.51 & 0.85 & $0.60(0.35,1.05)$ \\
\hline Hospitalization for heart failure or CV death & $55(2.63)$ & $64(3.05)$ & 1.41 & 1.65 & $0.86(0.60,1.23)$ \\
\hline
\end{tabular}

a Patient-years is calculated as the sum of all patients follow-up time to event. For patients without an event, the time to event is the last follow-up time as defined for ITT population in the statistical analysis plan

b Based on the proportional hazards model that includes treatment as an explanatory factor

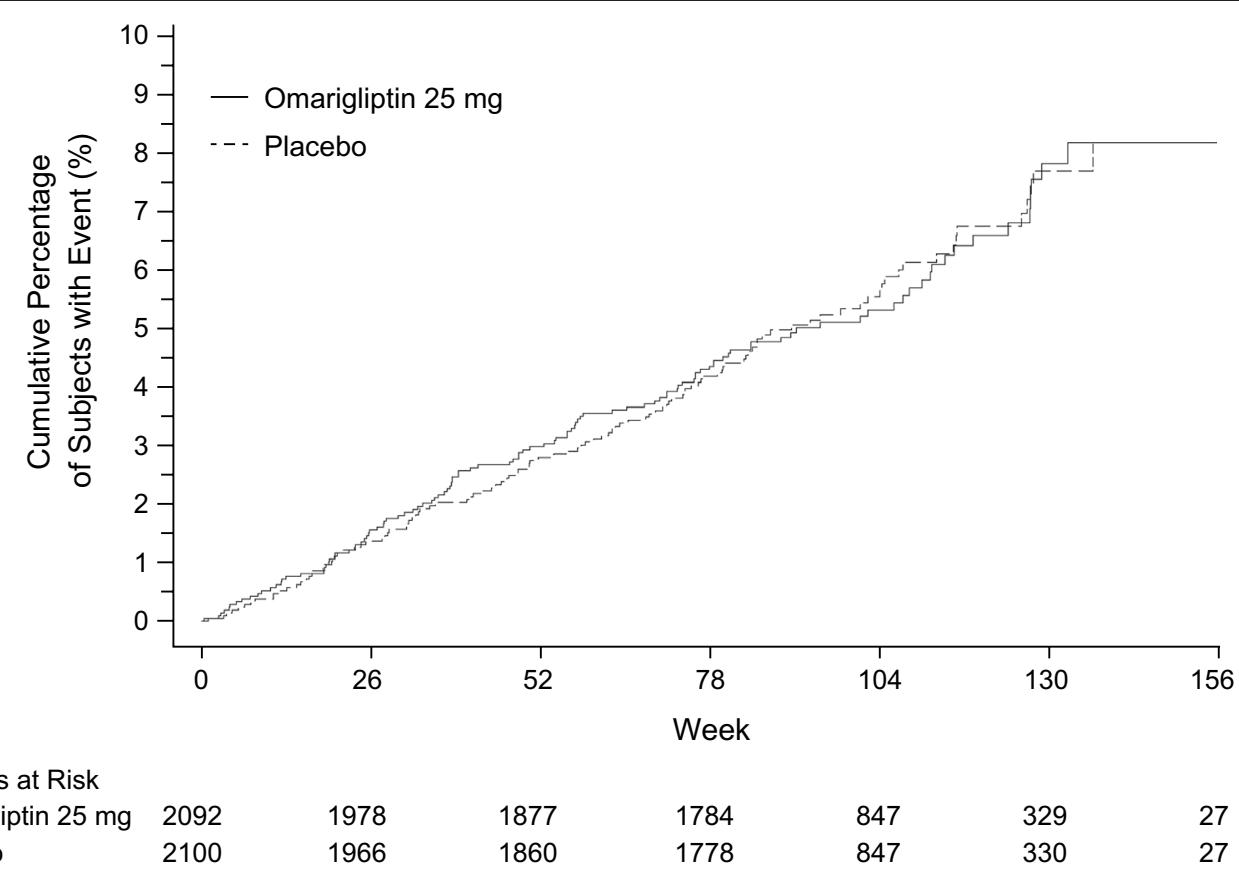

Fig. 2 Kaplan-Meier plot of time to first major adverse cardiac event in the intention-to-treat population

between treatment difference of $-0.30 \%(-0.46,-0.14)$. Over time, an increase in HbAlc was observed in both treatment groups.

\section{Non-cardiovascular safety}

In the following, the term "higher" indicates that the 95\% $\mathrm{CI}$ for the between-group difference in the incidences of adverse events excluded 0 . Adverse event summary measures were similar in the omarigliptin and placebo group, with the exception of drug-related adverse events, which was higher in the omarigliptin group compared with the placebo group (Table 4). The between-group difference in the overall incidence of drug-related adverse events was primarily due to differences in the adverse event of hypoglycemia.

The number of patients with adverse events by MedDRA system organ class (SOC) was similar between the omarigliptin and placebo groups, with the exception of skin and subcutaneous tissue disorders SOC, where the incidence was higher in the omarigliptin group compared with the placebo group $(7.9 \%$ [166/2092 patients] versus $6.0 \%$ $[126 / 2100$ patients]) due to a variety of specific adverse 


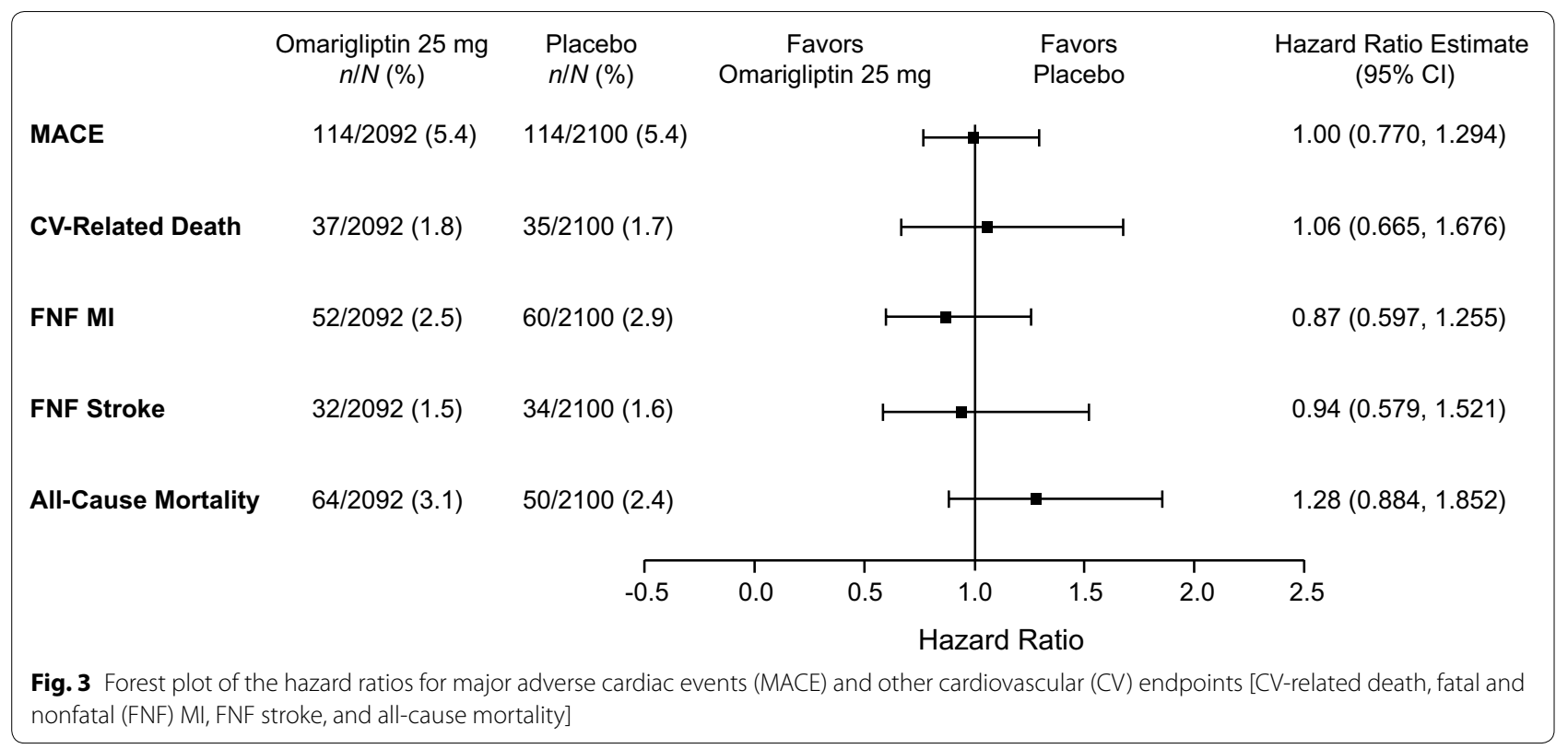

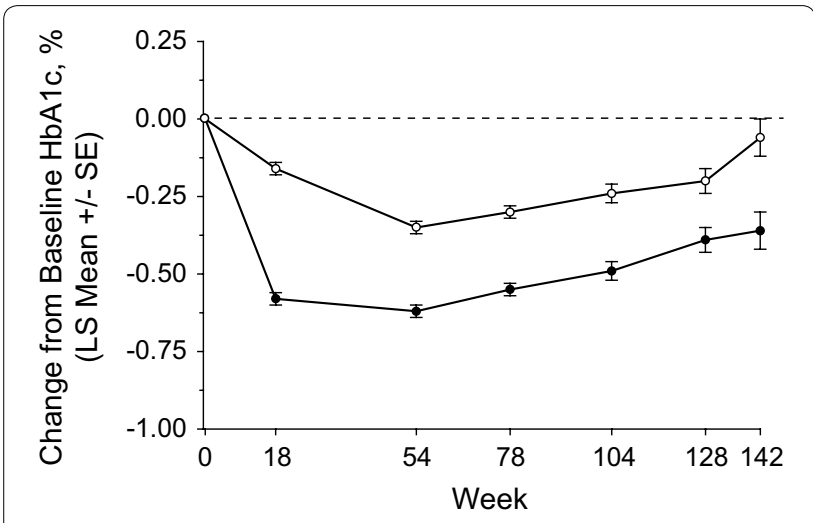

Fig. 4 Changes from baseline in HbA1c over time; filled circle omarigliptin 25 mg q.w., open circle placebo

events. The majority of cutaneous adverse events in the omarigliptin group were non-serious; however 2 (1 eczema and 1 dermatosis) were serious, but were not considered by the investigator to be related to study medication and did not lead to the discontinuation of study medication.

Among the specific adverse events, the incidence of the adverse event of AST increased was higher in the omarigliptin group compared with the placebo group (Table 5). The between-group difference in adverse event of ALT increased was less notable and there were no notable between-group differences in the incidences of exceeding the predefined limits of change (PDLC) for ALT or AST of $\geq 3 \times$ ULN or $\geq 5 \times$ ULN. Including supplemental laboratory data (measurements entered in the database from sources other than the central laboratory; primarily drawn during hospitalization), there were 16
Table 4 Adverse event (AE) summary measures in the APaT population; Treatment Period +21 days

\begin{tabular}{|c|c|c|c|}
\hline Patients, $n(\%)$ & $\begin{array}{l}\text { Omarigliptin } \\
N=2092\end{array}$ & $\begin{array}{l}\text { Placebo } \\
N=2100\end{array}$ & Difference $^{a}$ \\
\hline \multicolumn{4}{|l|}{ With one or more } \\
\hline AEs & $1605(77.2)$ & $1583(75.4)$ & $1.8(-0.8,4.4)$ \\
\hline Drug-related ${ }^{\mathrm{b}} \mathrm{AEs}$ & $268(12.8)$ & $215(10.2)$ & $2.6(0.6,4.5)$ \\
\hline Serious AEs & $476(22.8)$ & $467(22.2)$ & $0.5(-2.0,3.0)$ \\
\hline Serious drug-related ${ }^{b} A E s$ & $8(0.4)$ & $6(0.3)$ & $0.1(-0.3,0.5)$ \\
\hline Who died & $39(1.9)$ & $30(1.4)$ & $0.4(-0.3,1.2)$ \\
\hline \multicolumn{4}{|l|}{ Who discontinued due to } \\
\hline $\mathrm{An} A \mathrm{E}$ & $77(3.7)$ & $68(3.2)$ & $0.4(-0.7,1.6)$ \\
\hline A drug-related ${ }^{\mathrm{b}} \mathrm{AE}$ & $21(1.0)$ & $18(0.9)$ & $0.1(-0.5,0.8)$ \\
\hline A serious $A E$ & $37(1.8)$ & $28(1.3)$ & $0.4(-0.3,1.2)$ \\
\hline A serious drug-related ${ }^{b} A E$ & $3(0.1)$ & $1(0.0)$ & 0.1 \\
\hline
\end{tabular}

${ }^{a}$ Difference in \% vs. placebo; estimate $(95 \% \mathrm{Cl})$ was computed only for $\mathrm{AE}$ summary endpoints with at least four patients having events in one or more treatment groups

${ }^{\mathrm{b}}$ Assessed by the investigator as related to study drug

patients in the omarigliptin group and 17 patients in the placebo group with ALT $\geq 5 \times \mathrm{ULN}$; all of the patients in the omarigliptin group had a plausible alternative explanation (e.g., acute cholecystitis, alcohol abuse, metastatic cancer) and/or resolved on study medication. There were no cases that met the combined criteria for a Hy's law case (i.e., ALT or AST $\geq 3 \times$ ULN with elevations in bilirubin $\geq 2 \times$ ULN and alkaline phosphatase $<2 \times$ ULN without alternative explanation) that would suggest the potential for drug-induced liver injury [11]. There were no between-group differences in mean change from baseline over time in ALT or AST. 
Table 5 Incidences of adverse events related to alanine aminotransferase (ALT) and aspartate aminotransferase (AST) and predefined limits of change for those liver tests in the APaT population, Treatment Period + 21 days; and change from baseline in ALT and AST at Week 54

\begin{tabular}{lcr}
\hline Adverse event, $\boldsymbol{n}$ (\%) & $\begin{array}{c}\text { Omarigliptin } \\
\boldsymbol{N = \mathbf { 2 0 9 2 }}\end{array}$ & $\begin{array}{c}\text { Placebo } \\
\boldsymbol{N}=\mathbf{2 1 0 0}\end{array}$ \\
\hline ALT increased & $24(1.1)$ & $16(0.8)$ \\
AST increased & $16(0.8)$ & $4(0.2)$ \\
Predefined limit of change & & \\
ALT $\geq 3 \times$ ULN & $35(1.7)$ & $34(1.6)$ \\
AST $\geq 3 \times$ ULN & $19(0.9)$ & $16(0.8)$ \\
ALT $\geq 5 \times$ ULN & $14(0.7)$ & $12(0.6)$ \\
AST $\geq 5 \times$ ULN & $10(0.5)$ & $6(0.3)$ \\
ALT $\geq 5 \times$ ULN & $16(0.7)$ & $17(0.8)$ \\
Mean change from baseline (SD) at Week $54^{\mathrm{b}}(\mathrm{IU} / \mathrm{L})$ & \\
ALT & $-0.6(15.2)$ & $-0.6(12.5)$ \\
AST & $0.2(14.5)$ & $-0.4(9.7)$ \\
\hline
\end{tabular}

Central laboratory normal range: ALT 10-40 IU/L (male) and 10-33 IU/L (female); AST 10-43 IU/L (male) and 10-36 IU/L (female)

a Including supplemental laboratory data

${ }^{b}$ Mean changes based on $n=1801$ in the omarigliptin group and $n=1756$ in the placebo group

Table 6 summarizes the adverse events of hypoglycemia. The incidence of symptomatic hypoglycemia was higher in the omarigliptin group (22.6\% [472/2092

Table 6 Analysis of adverse events (AEs) of hypoglycemia in the APaT population Treatment Period + 21 days

\begin{tabular}{|c|c|c|c|}
\hline Patients, $n$ (\%) & $\begin{array}{l}\text { Omarigliptin } \\
N=2092\end{array}$ & $\begin{array}{l}\text { Placebo } \\
N=2100\end{array}$ & Difference $^{a}$ \\
\hline $\begin{array}{l}\text { With one or more AEs of } \\
\text { hypoglycemia }\end{array}$ & $513(24.5)$ & $454(21.6)$ & $2.9(0.4,5.5)$ \\
\hline Symptomatic $c^{b}$ & $472(22.6)$ & $414(19.7)$ & $2.8^{f}(0.4,5.3)$ \\
\hline $\begin{array}{l}\text { Documented } \\
\text { symptomatic }^{c}\end{array}$ & $447(21.4)$ & $387(18.4)$ & $2.9(0.5,5.4)$ \\
\hline Severe $^{d}$ & $88(4.2)$ & $70(3.3)$ & $0.9(-0.3,2.0)$ \\
\hline $\begin{array}{l}\text { Requiring non-medical } \\
\text { assistance }\end{array}$ & $82(3.9)$ & $58(2.8)$ & $1.2(0.1,2.3)$ \\
\hline $\begin{array}{l}\text { Requiring medical } \\
\text { assistance }\end{array}$ & $11(0.5)$ & $19(0.9)$ & $-0.4(-0.9,0.1)$ \\
\hline Asymptomatic ${ }^{e}$ & $126(6.0)$ & $123(5.9)$ & $0.2(-1.3,1.6)$ \\
\hline
\end{tabular}

a Difference in \% vs. placebo

b Symptomatic hypoglycemia: episode with clinical symptoms attributed to hypoglycemia, without regard to glucose level

c Documented symptomatic: episode with clinical symptoms attributed to hypoglycemia with a documented glucose levels of $\leq 3.9 \mathrm{mmol} / \mathrm{L}$ ( $\leq 70 \mathrm{mg} / \mathrm{dL}$ )

d Severe hypoglycemia: episode that required assistance, either medical or nonmedical. Episodes with a markedly depressed level of consciousness, a loss of consciousness, or seizure were classified as having required medical assistance, whether or not medical assistance was obtained

e Asymptomatic hypoglycemia: finger stick glucose values $\leq 3.9 \mathrm{mmol} / \mathrm{L}$ (70 $\mathrm{mg} / \mathrm{dL}$ ) without symptoms

$\mathrm{f} p=0.024$ patients]) compared with the placebo group (19.7\% [414/2100 patients]); $\mathrm{p}=0.024$. The incidence of severe hypoglycemia requiring medical assistance was $4.2 \%$ (88/2092 patients) in the omarigliptin group compared to $3.3 \%$ in $(70 / 2100$ patients) in the placebo group.

Table 7 summarizes the events of adjudication-confirmed acute and chronic pancreatitis and adjudication-confirmed prespecified hypersensitivity reactions. Confirmed acute pancreatitis events were uncommon overall and none of the cases in either treatment group were fatal. One patient in the placebo group had confirmed chronic pancreatitis (no cases occurred in the omarigliptin group).

Four patients in the omarigliptin group had a confirmed case of angioedema; all were nonserious and one case occurred in the post-treatment period (i.e., after the 21-day follow-up after discontinuation of study medication). One patient in the placebo group had two confirmed cases of angioedema; both of these cases were serious adverse events. Two patients in the omarigliptin group with a history of asthma had events of confirmed asthma-bronchospasm; one was reported as non-serious and the other as a serious adverse event. Two patients in the placebo group had confirmed cases of asthmabronchospasm; both were reported as non-serious. One patient in the placebo group had a confirmed case of anaphylactic reaction.

Investigator reported pancreatic cancer occurred in five patients in the omarigliptin group (3 cases of pancreatic carcinoma and 2 cases of pancreatic cancer metastatic) and one patient in the placebo group ( 1 case of pancreatic carcinoma).

There were no clinically meaningful changes from baseline or in analysis of PDLC in laboratory safety measures. Small changes from baseline in mean serum amylase and lipase values were observed in the omarigliptin group by

Table 7 Incidences of adjudication-confirmed cases of pancreatitis and prespecified hypersensitivity adverse events in the APaT population; Treatment Period + all follow-up days

\begin{tabular}{lll}
\hline Patients, $\mathbf{n}(\%)$ & $\begin{array}{l}\text { Omarigliptin } \\
\mathbf{N = 2 0 9 2}\end{array}$ & $\begin{array}{l}\text { Placebo } \\
\boldsymbol{N}=\mathbf{2 1 0 0}\end{array}$ \\
\hline With pancreatitis & & \\
$\quad$ Acute & $6(0.3)$ & $3(0.1)$ \\
Chronic & $0(0.0)$ & $1(<0.1)$ \\
With hypersensitivity & & \\
Angioedema & $4(0.2)$ & $1^{\mathrm{a}}(0.1)$ \\
Asthma-bronchospasm & $2(0.1)$ & $2(0.1)$ \\
Anaphylaxis & $0(0.0)$ & $1(<0.1)$ \\
\hline
\end{tabular}

a One patient in the placebo group was reported to have experienced two cases of angioedema 
Table 8 Mean (IU/L) \pm standard deviation serum amylase and lipase values through Week 156

\begin{tabular}{|c|c|c|c|c|}
\hline \multirow[t]{2}{*}{ Week } & \multicolumn{2}{|c|}{ Serum amylase } & \multicolumn{2}{|l|}{ Serum lipase } \\
\hline & $\begin{array}{l}\text { Omarigliptin } \\
N=2092\end{array}$ & $\begin{array}{l}\text { Placebo } \\
N=2100\end{array}$ & $\begin{array}{l}\text { Omarigliptin } \\
N=2092\end{array}$ & $\begin{array}{l}\text { Placebo } \\
N=2100\end{array}$ \\
\hline 0 & $\begin{array}{l}66.5 \pm 33.3 \\
n=1465\end{array}$ & $\begin{array}{l}67.5 \pm 39.2 \\
n=1457\end{array}$ & $\begin{array}{l}45.1 \pm 35.4 \\
n=1465\end{array}$ & $\begin{array}{l}45.5 \pm 53.5 \\
n=1457\end{array}$ \\
\hline 6 & $\begin{array}{l}71.3 \pm 34.0 \\
n=1353\end{array}$ & $\begin{array}{l}66.7 \pm 35.1 \\
n=1338\end{array}$ & $\begin{array}{l}53.4 \pm 45.6 \\
n=1353\end{array}$ & $\begin{array}{l}45.1 \pm 50.1 \\
n=1337\end{array}$ \\
\hline 12 & $\begin{array}{l}72.9 \pm 35.8 \\
n=1329\end{array}$ & $\begin{array}{l}68.1 \pm 42.7 \\
n=1301\end{array}$ & $\begin{array}{l}56.2 \pm 49.9 \\
n=1329\end{array}$ & $\begin{array}{l}46.4 \pm 41.7 \\
n=1300\end{array}$ \\
\hline 18 & $\begin{array}{l}71.6 \pm 35.3 \\
n=1314\end{array}$ & $\begin{array}{l}67.4 \pm 35.2 \\
n=1281\end{array}$ & $\begin{array}{l}52.1 \pm 42.2 \\
n=1313\end{array}$ & $\begin{array}{l}45.1 \pm 39.0 \\
n=1280\end{array}$ \\
\hline 24 & $\begin{array}{l}72.0 \pm 34.8 \\
n=1305\end{array}$ & $\begin{array}{l}67.6 \pm 33.4 \\
n=1296\end{array}$ & $\begin{array}{l}55.6 \pm 52.5 \\
n=1305\end{array}$ & $\begin{array}{l}45.5 \pm 35.0 \\
n=1295\end{array}$ \\
\hline 32 & $\begin{array}{l}71.3 \pm 33.7 \\
n=1308\end{array}$ & $\begin{array}{l}68.1 \pm 34.8 \\
n=1292\end{array}$ & $\begin{array}{l}51.4 \pm 33.2 \\
n=1308\end{array}$ & $\begin{array}{l}46.4 \pm 42.9 \\
n=1292\end{array}$ \\
\hline 40 & $\begin{array}{l}70.9 \pm 35.4 \\
n=1289\end{array}$ & $\begin{array}{l}67.1 \pm 33.8 \\
n=1261\end{array}$ & $\begin{array}{l}51.3 \pm 37.5 \\
n=1289\end{array}$ & $\begin{array}{l}43.7 \pm 29.3 \\
n=1261\end{array}$ \\
\hline 48 & $\begin{array}{l}71.6 \pm 34.6 \\
n=1282\end{array}$ & $\begin{array}{l}67.5 \pm 35.9 \\
n=1235\end{array}$ & $\begin{array}{l}54.2 \pm 54.2 \\
n=1280\end{array}$ & $\begin{array}{l}44.6 \pm 36.1 \\
n=1236\end{array}$ \\
\hline 54 & $\begin{array}{l}74.1 \pm 52.6 \\
n=1292\end{array}$ & $\begin{array}{l}68.2 \pm 33.5 \\
n=1253\end{array}$ & $\begin{array}{l}56.3 \pm 185.2 \\
n=1291\end{array}$ & $\begin{array}{l}44.1 \pm 37.9 \\
n=1253\end{array}$ \\
\hline 66 & $\begin{array}{l}72.8 \pm 35.8 \\
n=1263\end{array}$ & $\begin{array}{l}68.8 \pm 42.4 \\
n=1229\end{array}$ & $\begin{array}{l}54.3 \pm 56.3 \\
n=1260\end{array}$ & $\begin{array}{l}44.5 \pm 37.1 \\
n=1229\end{array}$ \\
\hline 78 & $\begin{array}{l}75.1 \pm 57.9 \\
n=1339\end{array}$ & $\begin{array}{l}67.5 \pm 33.9 \\
n=1297\end{array}$ & $\begin{array}{l}53.4 \pm 50.2 \\
n=1339\end{array}$ & $\begin{array}{l}47.2 \pm 61.9 \\
n=1294\end{array}$ \\
\hline 90 & $\begin{array}{l}72.1 \pm 38.0 \\
n=836\end{array}$ & $\begin{array}{l}69.1 \pm 38.8 \\
n=808\end{array}$ & $\begin{array}{l}57.4 \pm 74.0 \\
n=835\end{array}$ & $\begin{array}{l}46.1 \pm 40.5 \\
n=808\end{array}$ \\
\hline 104 & $\begin{array}{l}74.8 \pm 85.9 \\
n=612\end{array}$ & $\begin{array}{l}68.3 \pm 42.1 \\
n=568\end{array}$ & $\begin{array}{l}72.3 \pm 437.2 \\
n=611\end{array}$ & $\begin{array}{l}45.1 \pm 32.6 \\
n=568\end{array}$ \\
\hline 116 & $\begin{array}{l}74.7 \pm 38.2 \\
n=376\end{array}$ & $\begin{array}{l}65.5 \pm 30.8 \\
n=351\end{array}$ & $\begin{array}{l}59.0 \pm 84.0 \\
n=376\end{array}$ & $\begin{array}{l}46.6 \pm 54.2 \\
n=351\end{array}$ \\
\hline 128 & $\begin{array}{l}75.7 \pm 36.2 \\
n=213\end{array}$ & $\begin{array}{l}64.1 \pm 32.7 \\
n=223\end{array}$ & $\begin{array}{l}58.4 \pm 52.6 \\
n=213\end{array}$ & $\begin{array}{l}42.9 \pm 24.5 \\
n=223\end{array}$ \\
\hline 142 & $\begin{array}{l}70.7 \pm 30.8 \\
n=69\end{array}$ & $\begin{array}{l}71.7 \pm 54.2 \\
n=55\end{array}$ & $\begin{array}{l}52.8 \pm 31.2 \\
n=69\end{array}$ & $\begin{array}{l}44.0 \pm 25.9 \\
n=55\end{array}$ \\
\hline 156 & $\begin{array}{l}70.0 \pm \mathrm{N} / \mathrm{A} \\
n=1\end{array}$ & $\begin{array}{l}41.0 \pm N / A \\
n=1\end{array}$ & $\begin{array}{l}31.0 \pm \mathrm{N} / \mathrm{A} \\
n=1\end{array}$ & $\begin{array}{l}9.0 \pm N / A \\
n=1\end{array}$ \\
\hline
\end{tabular}

Measurement of amylase and lipase was added to the protocol after study initiation at the request of several European countries; therefore not all patients had baseline values

Central laboratory normal range: serum amylase $=35-121 \mathrm{U} / \mathrm{L}$; serum lipase $=13-60 \mathrm{U} / \mathrm{L}$

Week 6 and continued through Week 156 (Table 8). All mean serum amylase values over time were within the normal laboratory range (35-121 U/L) throughout the treatment period in both treatment groups. The mean serum lipase value was within the normal laboratory range (13-60 U/L) in both treatment groups throughout the treatment period except for the omarigliptin group at Week 104, when the mean value (72.3 IU/L \pm 437.2$)$ was slightly greater than the upper limit of the normal range.

There were no clinically meaningful between-group changes from baseline in eGFR at any timepoint. At Week
142, the LS mean change from baseline (SE) in eGFR calculated by the MDRD equation $\left(\mathrm{mL} / \mathrm{min} / 1.73 \mathrm{~m}^{2}\right)$ was -0.97 (1.05) in the omarigliptin group and 1.45 (1.06) in the placebo group; LS mean difference ( $95 \% \mathrm{CI}$ ) was $-2.43(-5.36,0.51)$.

There were no clinically meaningful changes from baseline over time in heart rate, blood pressure, or ECG intervals (including QTc) in either treatment group. At Week 142, the LS mean changes (SE) from baseline in body weight were $-0.33 \mathrm{~kg}(0.21)$ in the omarigliptin group and $-0.25 \mathrm{~kg}(0.22)$ in the placebo group.

\section{Discussion}

The results of this study suggest that treatment of patients with T2DM and established CV disease with onceweekly omarigliptin is not associated with an increased risk of MACE. These results are consistent with the three completed CV outcome studies with daily DPP-4 inhibitors [4-6]. The 1.5 years median follow-up of this study due to its early termination is shorter than that of the completed CV safety studies with similar designs and patient populations for the DPP-4 inhibitors saxagliptin (SAVOR-TIMI 53) [6] and sitagliptin (TECOS) [4], which had median follow-ups of 2.1 and 3.0 years, respectively, but was similar to the median follow-up in EXAMINE [5], although the latter study enrolled a different (postACS) population.

In this study, analysis was performed on approximately $36 \%$ (i.e., a total of 228 confirmed CV events) of the 632 confirmed $\mathrm{CV}$ events projected to be needed to provide $>90 \%$ power to demonstrate non-inferiority. As is the case with any early-terminated safety study, the effects of treatment on endpoints observed during the period prior to study termination might differ from those observed at later timepoints. Nonetheless, in the present study a high degree of consistency in the rate of $\mathrm{CV}$ events was observed between treatment groups up until the time of study termination, and the observed profile of accrued $\mathrm{CV}$ events over time was consistent with that of previously completed CV safety studies.

In this study, there was no increase observed in the risk of hHF, although the number of confirmed first events of hHF was modest. Nonetheless, the results of the study are consistent with the results of TECOS, which did not show an increased risk of hHF with sitagliptin [4].

The analysis of the change from baseline in HbA1c indicates omarigliptin provided a clinically meaningful reduction in HbA1c throughout the treatment period. In the first 18 weeks of the study, during which time the effects of omarigliptin therapy on HbA1c would be expected to achieve near-maximum, investigators were instructed not to adjust background AHAs unless required to avoid hypoglycemia or excessive 
hyperglycemia. As anticipated, the largest between-group difference in HbA1c was observed at Week $18(-0.43 \%)$. Subsequently, despite the fact that investigators were encouraged to adjust AHAs after Week 18 to meet individualized patient goals, a between-group difference in HbA1c persisted throughout the treatment period.

The present study provided a sizable database for an analysis of non-CV safety. The analysis of hypoglycemia suggests that omarigliptin has a favorable profile compared with placebo on a background of a variety of diabetes medications, including insulin. The incidence of symptomatic hypoglycemia in the omarigliptin group compared with the placebo group $(22.6 \%$ vs. $19.7 \%)$ is consistent with previous observations of daily DPP-4 inhibitors, which can be associated with an increased risk of hypoglycemia when co-administered with drugs that are associated with hypoglycemia, such as insulin and sulfonylureas [12-14]. Approximately $39 \%$ of patients in both treatment groups were treated with insulin and $42 \%$ were treated with a sulfonylurea.

The observed imbalance in the incidence of the adverse event of AST increased prompted a detailed review of other liver test-related adverse events and a review of PDLC and mean changes from baseline in liver tests. No imbalances were observed in the PDLC for liver tests, which is an objective assessment of those measures, as opposed to adverse events, which are a more subjective measure due to investigator discretion about reporting an abnormal laboratory value as an adverse event. No cases meeting the definition of Hy's law [11] were identified. The conclusion from this review is that omarigliptin does not pose a risk for clinically important liver events.

In past years, the topic of pancreatic safety of incretin therapies has been raised [15]. The results of this study indicate that acute (6 omarigliptin versus 3 placebo) and chronic pancreatitis (0 omarigliptin versus 1 placebo) are infrequent events. The results of this study could be interpreted to be consistent with the meta-analyses of the three completed CV outcome studies [8], in which a small absolute increase in risk was observed with DPP-4 inhibitor therapy. In this study, pancreatic cancer was also infrequent, but an imbalance in the number of pancreatic cancers was observed (5 patients receiving omarigliptin and 1 patient receiving placebo). The relatively early times of onset of the pancreatic malignancies in the omarigliptin group after initiation of therapy (e.g., 3 cases were diagnosed after $<1$ year of treatment) is not suggestive of a relationship to study drug.

\section{Conclusion}

In the present study conducted in patients with T2DM and established CV disease, treatment with omarigliptin $25 \mathrm{mg}$ q.w., when used as part of usual diabetes care, did not increase the risk of MACE or the risk of hHF compared with placebo. Omarigliptin was generally well tolerated, with an incidence of hypoglycemia that was consistent with the experience with other DPP-4 inhibitors. These results, conducted in a population of patients with T2DM and established CV disease, while not definitive because of early study termination, nonetheless contribute to the existing dataset supporting the safety of the DPP-4 inhibitor drug class. Further studies are required to determine why differences have been observed across studies conducted with different DPP-4 inhibitors.

\section{Additional file}

Additional file 1. Adjudication guidelines for cardiac events.

\section{Abbreviations}

ACS: acute coronary syndrome; AE: adverse event; AGl: alpha-glucosidase inhibitor; AHA: anti-hyperglycemic agent; ALT: alanine aminotransferase; APaT: all-patients-as-treated; AST: aspartate aminotransferase; BMI: body mass index; CABG: coronary artery bypass graft; CAC: Clinical Adjudication Committee; Cl: confidence interval; CV: cardiovascular; DPP-4: dipeptidyl peptidase-4; ECG: electrocardiogram; eGFR: estimated glomerular filtration rate; EXAMINE: Examination of Cardiovascular Outcomes with Alogliptin versus Standard of Care; FFSG: fasting-fingerstick glucose; FNF: fatal/nonfatal; HbA1c: glycated hemoglobin; hHF: hospitalization for heart failure; HR: hazard ratio; ITT: intent-to-treat; LS: least squares; MACE: major adverse cardiac events; MedDRA: Medical Dictionary for Regulatory Activities; MDRD: Modification of Diet in Renal Disease; MF: metformin; MI: myocardial infarction; NPH: normal pressure hydrocephalus; PDLC: predefined limits of change; PIO: pioglitazone; PTCA: percutaneous transluminal coronary angioplasty; q.w.: once weekly; QTc: corrected QT interval; SAVOR-TIMI 53: Saxagliptin Assessment of Vascular Outcomes Recorded in patients with diabetes mellitus-Thrombolysis in Myocardial Infarction; SD: standard deviation; SE: standard error; SGLT2i: sodium-glucose cotransporter 2 inhibitor; SOC: system organ class; T2DM: type 2 diabetes mellitus; TECOS: Trial Evaluating Cardiovascular Outcomes with Sitagliptin; ULN: upper limit of normal; US: United States.

\section{Authors' contributions}

IG contributed to the conception, design, or planning of the study, acquisition and analysis of the data, interpretation of the results, drafting of the manuscript, and critically reviewed or revised the manuscript. MC contributed to the analysis of the data, the interpretation of the results, and critically reviewed or revised the manuscript. S Suryawanshi and KDK contributed to the conception, design, or planning of the study, interpretation of the results, and critically reviewed or revised the manuscript. CN and S Shah contributed to the interpretation of results, and critically reviewed or revised the manuscript. EAO contributed to the interpretation of results and the drafting of the manuscript. SSE and EL contributed to the conception, design, or planning of the study, and critically reviewed or revised the manuscript. All authors agree to be accountable for all aspects of the work in ensuring that questions related to the accuracy or integrity of any part of the work are appropriately investigated and resolved. All authors read and approved the final manuscript.

\footnotetext{
Author details

${ }^{1}$ Merck \& Co., Inc., Kenilworth, NJ, USA. ${ }^{2}$ Merck \& Co., Inc., RY34-A260, P.O. Box 2000, Rahway, NJ 07065, USA. ${ }^{3}$ Merck \& Co., Inc., RY34-A304, P.O. Box 2000, Rahway, NJ 07065, USA. ${ }^{4}$ Merck \& Co., Inc., RY34-A314, P.O. Box 2000, Rahway, NJ 07065, USA. ${ }^{5}$ Merck \& Co., Inc., RY34A-228, P.O. Box 2000, Rahway, NJ 07065, USA. ${ }^{6}$ Merck \& Co., Inc., RY34-A578, P.O. Box 2000, Rahway, NJ 07065, USA.

${ }^{7}$ Merck \& Co., Inc., RY34-A232, P.O. Box 2000, Rahway, NJ 07065, USA. ${ }^{8}$ Merck \& Co., Inc., RY34-A248, P.O. Box 2000, Rahway, NJ 07065, USA. ${ }^{9}$ Merck \& Co., Inc., RY34-A500, P.O. Box 2000, Rahway, NJ 07065, USA.
} 


\section{Acknowledgements}

Editorial assistance was provided by Jennifer Rotonda Ph.D. and Michele McColgan B.A. of Merck \& Co., Inc., Kenilworth, NJ, USA.

\section{Competing interests}

All authors are employees of Merck Sharp \& Dohme Corp., a subsidiary of Merck \& Co., Inc., Kenilworth, NJ, USA, who may own stock and/or hold stock options in the Company.

\section{Availability of data and materials}

Merck \& Co., Inc.'s data sharing policy, including restrictions, is available at http://engagezone.merck.com/ds_documentation.php. Requests for access to the study data can be submitted through the EngageZone site or via email to dataaccess@merck.com.

\section{Consent for publication}

All authors give their consent for publication.

\section{Ethics approval and consent to participate}

The study was conducted in accordance with the principles of Good Clinical Practice and was approved by the appropriate institutional review boards and regulatory agencies. All patients enrolled in the study provided written informed consent.

\section{Funding}

Funding for this trial was provided by Merck \& Co., Inc. Kenilworth, NJ, USA.

\section{Publisher's Note}

Springer Nature remains neutral with regard to jurisdictional claims in published maps and institutional affiliations.

Received: 4 August 2017 Accepted: 29 August 2017

Published online: 11 September 2017

\section{References}

1. Biftu T, Sinha-Roy R, Chen P, Qian X, Feng D, Kuethe JT, et al. Omarigliptin (MK-3102): a novel long-acting DPP-4 inhibitor for once-weekly treatment of type 2 diabetes. J Med Chem. 2014;57:3205-12.

2. Goldenberg R, Gantz I, Andryuk PJ, O'Neill EA, Kaufman KD, Lai E, et al. Randomized clinical trial comparing the efficacy and safety of treatment with the once-weekly dipeptidyl peptidase-4 (DPP-4) inhibitor omarigliptin or the once-daily DPP-4 inhibitor sitagliptin in patients with type 2 diabetes inadequately controlled on metformin monotherapy. Diabetes Obes Metab. 2017:19:394-400.

3. Gantz I, Okamoto T, Ito Y, Okuyama K, O'Neill EA, Kaufman KD, et al. A randomized, placebo- and sitagliptin-controlled trial of the safety and efficacy of omarigliptin, a once-weekly DPP-4 inhibitor, in Japanese patients with type 2 diabetes. Diabetes Obes Metab. 2017. doi:10.1111/ dom.12988.
4. Green JB, Bethel MA, Armstrong PW, Buse JB, Engel SS, Garg J, et al. Effect of sitagliptin on cardiovascular outcomes in type 2 diabetes. N Engl J Med. 2015:373:232-42.

5. White WB, Cannon CP, Heller SR, Nissen SE, Bergenstal RM, Bakris GL, et al. Alogliptin after acute coronary syndrome in patients with type 2 diabetes. N Engl J Med. 2013;369:1327-35.

6. Scirica BM, Bhatt DL, Braunwald E, Steg PG, Davidson J, Hirshberg B, et al. Saxagliptin and cardiovascular outcomes in patients with type 2 diabetes mellitus. N Engl J Med. 2013;369:1317-26.

7. Zannad F, Cannon CP, Cushman WC, Bakris GL, Menon V, Perez AT, et al. Heart failure and mortality outcomes in patients with type 2 diabetes taking alogliptin versus placebo in EXAMINE: a multicentre, randomised, double-blind trial. Lancet. 2015;385:2067-76.

8. Buse JB, Bethel MA, Green JB, Stevens SR, Lokhnygina Y, Aschner P, et al. Pancreatic safety of sitagliptin in the TECOS study. Diabetes Care. 2017:40:164-70.

9. Hicks KA, Hung HMJ, Mahaffey KW, Mehran R, Nissen SE, Stockbridge $\mathrm{NL}$, et al. Standardized definitions for cardiovascular and stroke end point events in clinical trials. https://pdfs.semanticscholar. org/efab/995c2062926101c1c28224e10b9732b47b59.pdf? $\mathrm{ga}=2.236088453 .524366300 .1496402363-1295595830.14964023632014$. Accessed 02 June 2017.

10. Thygesen K, Alpert JS, Jaffe AS, Simoons ML, Chaitman BR, White HD, et al. Third universal definition of myocardial infarction. Circulation. 2012;126:2020-35.

11. U.S. Food and Drug Administration. Guidance for Industry Drug-Induced Liver Injury: Premarketing Clinical Evaluation. 2009. https://www.fda.gov/ downloads/Drugs/.../guidances/UCM174090.pdf. Accessed 02 June 2017.

12. Owens DR, Swallow R, Dugi KA, Woerle HJ. Efficacy and safety of linagliptin in persons with type 2 diabetes inadequately controlled by a combination of metformin and sulphonylurea: a 24-week randomized study. Diabet Med. 2011:28:1352-61.

13. Moses RG, Round E, Shentu Y, Golm GT, O'Neill EA, Gantz I, et al. A randomized clinical trial evaluating the safety and efficacy of sitagliptin added to the combination of sulfonylurea and metformin in patients with type 2 diabetes mellitus and inadequate glycemic control. J Diabetes. 2016:8:701-11.

14. Hermansen K, Kipnes M, Luo E, Fanurik D, Khatami H, Stein P. Efficacy and safety of the dipeptidyl peptidase-4 inhibitor, sitagliptin, in patients with type 2 diabetes mellitus inadequately controlled on glimepiride alone or on glimepiride and metformin. Diabetes Obes Metab. 2007:9:733-45.

15. Egan AG, Blind E, Dunder K, de Graeff PA, Hummer BT, Bourcier T, et al. Pancreatic safety of incretin-based drugs-FDA and EMA assessment. N Engl J Med. 2014;370:794-7.

\section{Submit your next manuscript to BioMed Central and we will help you at every step:}

- We accept pre-submission inquiries

- Our selector tool helps you to find the most relevant journal

- We provide round the clock customer support

- Convenient online submission

- Thorough peer review

- Inclusion in PubMed and all major indexing services

- Maximum visibility for your research

Submit your manuscript at www.biomedcentral com/submit
Biomed Central 